\title{
Chapter 9 \\ European Mortality Forecasts: Are the Targets Still Moving?
}

\author{
Nico Keilman and Sigve Kristoffersen
}

\subsection{Introduction and Problem Formulation}

Many statistical agencies routinely produce population forecasts, and revise these forecasts when new data become available, or when current demographic trends indicate that an update is necessary. When the forecaster strongly revises, from one forecast round to the next one, a forecast for a certain target year (for instance the life expectancy in 2050), this indicates large uncertainty connected to mortality predictions. The aim of this chapter is to shed more light on the uncertainty in mortality forecasts, by analysing the extent to which life expectancy predictions for 2030 and 2050 were revised in subsequent rounds of population forecasts published by statistical agencies in selected countries. It updates and extends earlier work that focused on United Nations and Eurostat forecasts published between 1994 and 2004 (Keilman et al. 2008). There the conclusion was that life expectancy forecasts for 18 European countries for the year 2050 had been revised upwards systematically, by around 2 years on average during the 10-year publication period. A recent analysis based on official population forecasts for Norway published in the period 19992018 led to the same conclusion (Keilman 2018). Here we will show that the period of upward revisions seems to have ended for some European countries.

To predict the life expectancy for some future year appears to be similar to aiming at a moving target (Lee 1980). The forecaster tries to hit the value as well as she can, but we cannot expect that the first attempt will be successful. Next, there is a new attempt, but while the rifle was reloaded, the target appears to have moved upwards. This may go on for some forecast rounds. However, sometimes we notice hardly

\footnotetext{
N. Keilman $(\bowtie) \cdot$ S. Kristoffersen

Department of Economics, University of Oslo, Oslo, Norway

e-mail: nico.keilman@econ.uio.no; sigvekr@student.ikos.uio.no 
any revision from one forecast round to the next - in some cases, we even see a downward revision.

First, we illustrate this process with life expectancy assumptions for 2030 and 2050 included in official population forecasts of Austria, Denmark, the Netherlands, Norway, Sweden, and the United Kingdom. These countries were selected because the statistical agencies revise their population forecasts every 2 or 3 years. In addition, we show life expectancy assumptions for Japan, which is leading international trends in longevity. Next, we try to explain the systematic revisions by theories of anchoring (Tversky and Kahneman 1974; Kahneman 2011) and assumption drag (Ascher 1978).

\subsection{Findings}

Many methods have been used in the recent past to forecast mortality. Booth and Tickle (2008) give an extensive review. Most methods use some form of extrapolation: one assumes that the future trends in key parameters are a continuation of trends from the past. The key parameters could be age-specific mortality rates or the parameters in an underlying model. Some scholars have developed formal models for analysing current mortality trends in which risk factors and behavioural variables are linked to mortality at various ages, but such explanatory models are very rare in official demographic forecasts (the model employed by Statistics Netherlands is an exception; see below), for a number of reasons. These include the poor predictive performance of the models and the fact that future trends in explanatory variables (smoking, food habits, health care etc.) are as difficult to assess as future trends in mortality itself. See Bengtsson and Keilman (2019) for a recent overview.

Concerning the mortality forecasts presented here, the statistical agencies of Denmark, Japan, Netherlands, Norway, and Sweden use the Lee-Carter model (Lee and Carter 1992), or variations of it. The model variant used by Statistics Netherlands has two distinctive features: the role of smoking is explicitly modelled, and current trends in other countries than the Netherlands are included. The latter feature reduces the risk of extrapolating national idiosyncratic mortality trends. Mortality forecasts for Austria and the United Kingdom are based on assumed rates of decline in age-specific mortality rates in the future.

The Lee-Carter model assumes that a set of age-specific mortality rates observed for a number of years can be summarized in three sets of parameters. The first is a general age pattern of age-specific mortality, with one parameter value for each age. The second is a period index, with one parameter value for each year. The period index reflects falling mortality over time. However, the decrease is not the same for each age, and therefore the model contains an additional set of age-specific parameters, which modify the period index for each age. When used for projecting future mortality, one extrapolates the period index to future years, while keeping the two sets of age-specific parameters constant. Predicted age-specific mortality rates for a certain year can be summarized into a prediction for the life expectancy at birth 
(LE) for that year. The model has been criticized for under-projecting long-term life expectancies (and even short-term life expectancies when using long time series with historical mortality rates); see Stoeldraijer et al. (2018), and the references therein. During some years, the LE increased faster than in other years. Therefore, it is difficult to select a certain period that can be thought to be representative for the future. Moreover, the non-linear nature of the model tends to slow down the increase in predicted LE. The result is a concave curve that eventually shows a tendency towards "flattening out" in the longer term.

Extrapolation of mortality based on constant rates of decline in age-specific mortality also leads to a concave curve for the LE as a function of time. A proportional improvement in mortality makes less and less difference in the expectation of life (Keyfitz and Caswell 2005, 81).

In what follows, we will focus on LE-values for men and women for 2030 and for 2050. We would like to stress that the LE is not the primary mortality indicator deliberately set to some value by the statistical agencies. Rather, it summarizes extrapolated age-specific mortality rates that were set either directly (Austria, the UK) or indirectly (through the Lee-Carter model and its parameters; see above). We acknowledge that many different age patterns of mortality can lead to the same value of the LE - yet we focus on the latter measure because it is a simple and straightforward indicator for checking the plausibility of assumptions on future mortality.

\subsubsection{Descriptive Findings}

Figure 9.1 plots assumed values for the LE in 2049/2050 for men and women in a series of forecasts for the populations in Denmark, Japan, and Norway. The assumptions refer to official forecasts made by statistical agencies in the three countries during the period 2000-2018. The data come from various sources, as listed in the Appendix.
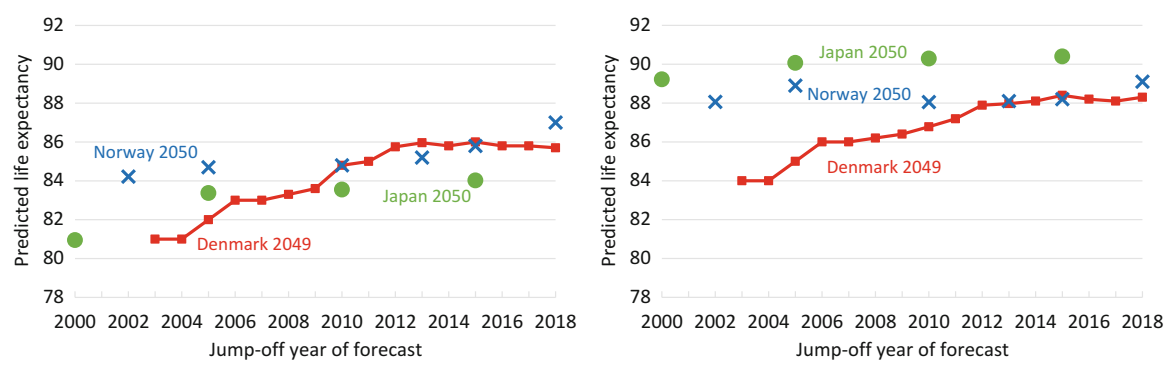

Fig. 9.1 Life expectancy predictions for Denmark, Norway, and Japan around 2050, forecasts prepared between 2000 and 2018. Left panel: men. Right panel: women. (Source: See Appendix) 

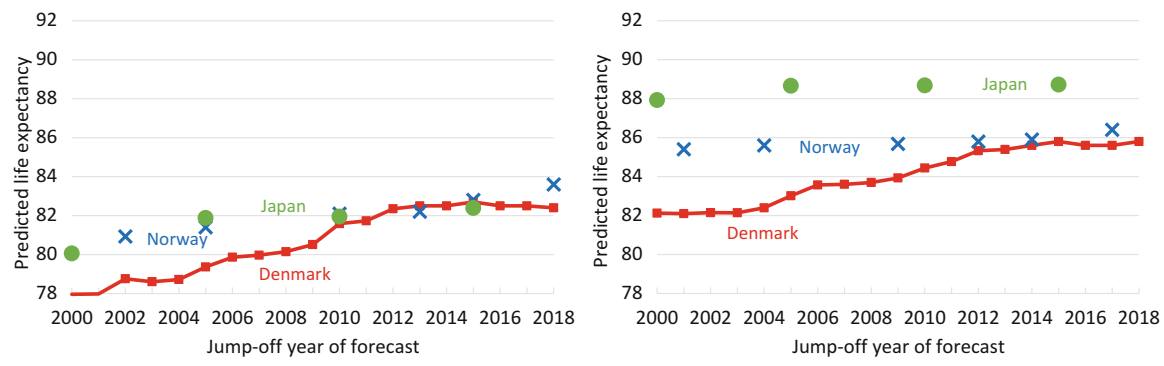

Fig. 9.2 Life expectancy predictions for Denmark, Norway, and Japan for the year 2030, forecasts prepared between 2000 and 2018. Left panel: men. Right panel: women. (Source: See Appendix)
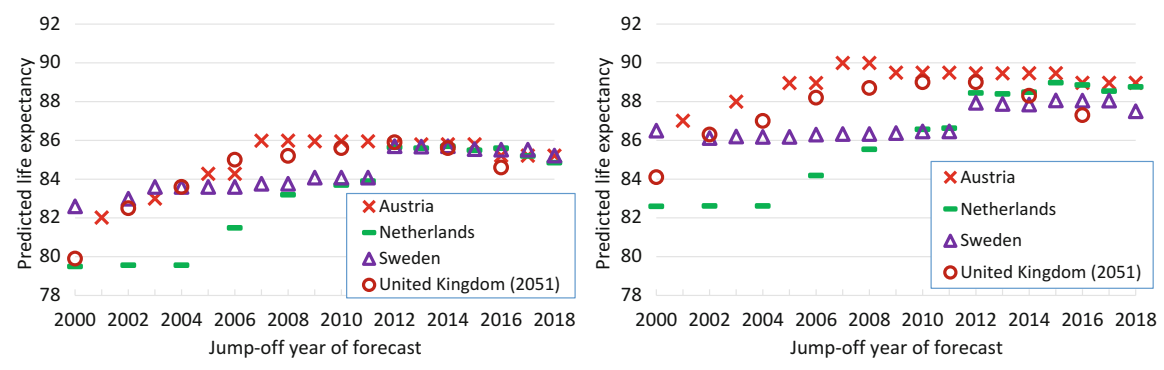

Fig. 9.3 Life expectancy predictions for Austria, the Netherlands, Sweden, and the United Kingdom around 2050, forecasts prepared between 2000 and 2018. Left panel: men. Right panel: women. (Source: See Appendix)

The graphs show a more or less systematic upward revision of LE-values from one forecast round to the next. For the case of Denmark, the upward trend appears to have ended around 2013. In the forecasts computed from 2013 onwards, there seems to be agreement about an LE for 2050 around 86 years for men and 88 years for women. For the other two countries, the forecasters show increased optimism in the sense that assumed LE-values were adjusted upwards in subsequent forecasts, although the revisions are not as strong as those for Denmark are during the period before 2013. One has to be a bit cautious concerning the LE of Japanese women, because we have only a few data points, and the upward revision from the 2010forecast to the 2015 -forecast is very modest.

The patterns that emerge for 2049/2050 in Fig. 9.1 are very similar to those for the year 2030 in the three countries; see Fig. 9.2. However, there is one exception: the 2030 predictions for Danish men computed between 2015 and 2018 show minor downward corrections. The "target" appears to move in opposite direction, compared to forecasts published before 2015.

Figures 9.3 and 9.4 show downward revisions in predicted LEs for 2030 and 2050 in four other countries: Austria, the Netherlands, Sweden, and the United Kingdom. The predictions for Austria appear to be the first ones for which upward revisions came to a halt: for both target years 2030 and 2050, this is visible starting 

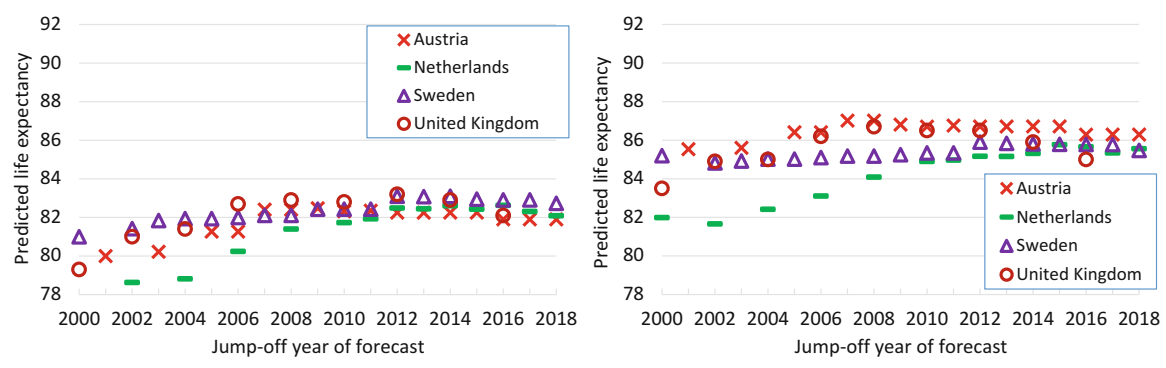

Fig. 9.4 Life expectancy predictions for Austria, the Netherlands, Sweden, and the United Kingdom for the year 2030, forecasts prepared between 2000 and 2018. Left panel: men. Right panel: women. (Source: See Appendix)

Fig. 9.5 Life expectancy at birth. (Source: See Appendix)

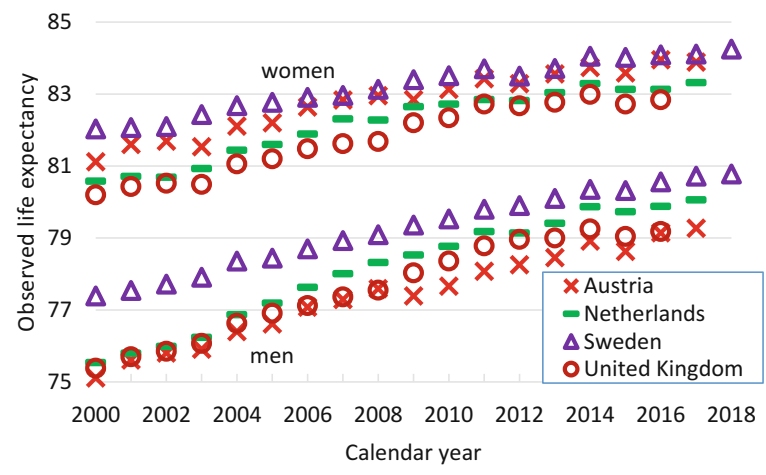

in 2007. Other countries followed a few years later. The cases of Sweden and the UK stand out with strong downward revisions in the last forecast, compared to the previous one. In the forecast of 2018, the 2050 LE-prediction for Swedish women was 0.55 years lower than the corresponding value in the forecast of 2017 . For men and women in the UK, the 2050 predictions for LE fell by a whole year between 2014 and 2016, which makes a downward slope of half a year of life per calendar year. These revisions are of similar magnitude as those for Austria between 2015 and 2016 (-0.58 years). Also, note that LE-assumptions in Figs. 9.1, 9.2, 9.3 and 9.4 seem to converge over time, with much larger differences between countries for forecasts computed in the first decade of the century than in later forecasts.

An obvious question is whether the patterns shown in Figs. 9.3 and 9.4 are related to trends in actually observed LEs for recent years. Figure 9.5 may shed some led on this. We note that the upward trend in LE has weakened in all four countries in recent years, perhaps with the exception of men in Sweden. Thus, a possible explanation of the flat or even decreasing trends in predicted LE in Figs. 9.3 and 9.4 might be the fact that increases in actual LE tend to slow down, at least for Austria, Netherlands, and the United Kingdom. In other words, forecasters are possibly strongly guided by trends in the current value of the LE, when they predict the LE for future years. In Sect. 9.3, we will suggest psychological explanations for these findings. 
Some evidence for an association between observed and predicted trends can be found in the justifications that statistical agencies give for the downward revisions. ONS (2017) writes, for the case of the United Kingdom, “ . . . actual life expectancy has increased less than projected since mid-2014; this means that the life expectancy values for 2016 are lower, and also reduces the rate of increase in subsequent years." Statistics Netherlands justifies the downward revision by referring to the unfavourable mortality development in the last months of 2016 and the limited decrease in mortality in the first 8 months of 2017. At the same time, relatively low mortality in 2014 (and a rather high LE that year) led to high values for predicted LEs in 2030 and 2050 in the 2015-based forecast, in particular for women. This effect disappeared in later forecasts (Stoeldraijer et al. 2017).

\subsubsection{A Simple Model}

The process can be formalized as follows. For simplicity, we assume linearity both for observed and for extrapolated life expectancy trajectories, but with different slopes. Consider a time interval $\left[\mathrm{t}_{0}, \mathrm{~T}\right]$, where $\mathrm{t}_{0}$ is a certain year in the past, and $\mathrm{T}$ is some future year ("target year"). A forecaster has data on actual life expectancy values $\mathrm{LE}(\mathrm{t})$ for the time interval $\left[\mathrm{t}_{0}, \mathrm{t}_{1}\right]$ and is faced with the task of predicting the life expectancy $\mathrm{LE}(\mathrm{t})$ to year $\mathrm{T}$, starting from the jump-off year $\mathrm{t}_{1}$. Assume that actual life expectancy LE(t) follows a straight line with slope $b>0$ on $\left[\mathrm{t}_{0}, \mathrm{~T}\right]$. Assume further that the extrapolated trajectory is a straight line on $\left[t_{1}, T\right]$ with slope $b_{e}>0$. Then the predicted life expectancy in year $T$, resulting from the prediction with jump-off year $t_{1}$, is $L_{1}(T)=L E\left(t_{1}\right)+\left(T-t_{1}\right) \cdot b_{e}$. An updated forecast is made in year $t_{2}>t_{1}$. The new extrapolation starts from $\operatorname{LE}\left(t_{2}\right)=\operatorname{LE}\left(t_{1}\right)+\left(t_{2}-t_{1}\right)$.b. The revised prediction for year $T$ is now

$$
\operatorname{LE}_{2}(T)=L E\left(t_{2}\right)+\left(T-t_{2}\right) \cdot b_{e}=L E\left(t_{1}\right)+\left(t_{2}-t_{1}\right) \cdot b+\left(T-t_{2}\right) \cdot b_{e}
$$

The revised forecast $\mathrm{LE}_{2}(\mathrm{~T})$ differs from the previous forecast $\mathrm{LE}_{1}(\mathrm{~T})$ by an amount of

$$
\mathrm{LE}_{2}(T)-\mathrm{LE}_{1}(T)=\left(\mathrm{t}_{2}-\mathrm{t}_{1}\right) \cdot \mathrm{b}+\left(\mathrm{T}-\mathrm{t}_{2}\right) \cdot \mathrm{b}_{\mathrm{e}}-\left(\mathrm{T}-\mathrm{t}_{1}\right) \cdot \mathrm{b}_{\mathrm{e}}=\left(\mathrm{t}_{2}-\mathrm{t}_{1}\right) \cdot\left(\mathrm{b}-\mathrm{b}_{\mathrm{e}}\right) .
$$

First, assume that $b_{e}<b$. The extrapolated life expectancy falls short compared to the actual life expectancy by an amount of $\left(b-b_{e}\right)$ annually. When the inter-forecast period is $\left(t_{2}-t_{1}\right)$ years, the new life expectancy forecast for year $T$ is higher than the previous one by $\left(t_{2}-t_{1}\right) .\left(b-b_{e}\right)$ years. This is the situation in Figs. 9.1 and 9.2.

Next, assume that life expectancy is extrapolated with the correct slope $\left(b_{e}=b\right)$. Then the new forecast for year $T$ is the same as the previous one: $\mathrm{LE}_{2}(\mathrm{~T})-\mathrm{LE}_{1}(\mathrm{~T})$. Much of the data in Figs. 9.3 and 9.4 reflect this pattern. 
Finally, assume that the increase in actual life expectance slows down, or even stagnates, whereas the extrapolations still follow a straight line with slope $b_{e}$. Then the difference $\left(b-b_{e}\right)$ may become negative, which implies a lower life expectancy forecast for year $\mathrm{T}$ compared to the previous forecast.

Note that the straight-line assumptions formulated above are not crucial for the qualitative results. As long as average annual increases over relevant time intervals are $b$ and $b_{e}$ for actual and extrapolated trends, respectively, we will see upward revisions for the predicted life expectancy in year $\mathrm{T}$ whenever the actual life expectancy improves faster than the extrapolated one $\left(b>b_{e}\right)$.

\subsection{Possible Explanations: Assumption Drag and Anchoring}

Why did population forecasters in the countries analysed here so often revise their views on people's length of life in an upwards direction? Or, to put it in terms of the simple model of Sect. 9.2.2: why did mortality forecasters under-predict so often the pace of annual LE-improvement? According to Pison (2018), French forecasters did not anticipate the sharp drop, after the Second World War, in adult mortality, old-age mortality in particular. There is no reason to assume that the situation was different in the seven countries analysed here until the beginning of this century. The decline in cardiovascular mortality explains much of the drop in adult mortality during the past 50 years. Falling numbers of cancer deaths contribute also. Forecasters did not foresee this decline, and relied heavily upon observed trends. Longevity improved only slowly during the 1950s and early 1960s, in particular for men. In some countries, there was even a stagnation or a decline. Examples are Denmark, the Netherlands, Norway, and Sweden. Therefore, forecasters assumed that the LE would increase very little in the immediate future, and that it would soon reach a maximum value ("ceiling", or "limit"; see Oeppen and Vaupel 2001). Indeed, statistical agencies in five of our countries used such a ceiling: Austria (until the 1990-based forecast, in which mortality was kept constant after 2015), Denmark (forecast of 1997, constant after 2012), Norway (forecast of 1990, constant after 2010), Netherlands (forecast of 1995, constant after 2010), and Sweden (forecast of 1994, constant after 2025). During the 1990s, however, the forecasters in these countries dropped the idea of a ceiling, and started to extrapolate a much longer increase in future LE, although the slope was not steep enough. French forecasters used an LE-ceiling up to the forecast published in 1986, but gave up this idea starting with the forecast published in 1995 (Pison 2018).

\subsubsection{Assumption Drag}

Forty years ago, Ascher (1978) analysed fertility forecasts in developed countries and noted that forecasters tend to rely strongly on recently observed data; they give 
less weight to the long-term trend. Figure 9.5 suggests that this "assumption drag" might hold for mortality, too: forecasters in Austria, the Netherlands, Sweden, and the UK revised assumed LE-values for 2030 and 2050 downwards, because they relied strongly on a weak upward trend of observed LEs in recent years. Here, "assumption drag" is to be understood as the maintenance of incorrect assumptions after their validity has been contradicted by the data. Why this practice? First, there might be a tendency among demographers to agree on incorrect assumptions because of socially validated beliefs, for example that there must be an upper limit to longevity, or a lower limit to fertility. Such a consensus makes it easier to reject conflicting evidence, such as new research results or data errors. Second, the complexity of advanced methods can mean that the results achieved are outdated, because all data are collected and processed and the high costs of advanced methods can mean that the forecasts simply tend to copy the underlying assumptions from a previous round.

Let us assume Ascher's assumption drag applies to mortality, too. The simple model of Sect. 9.2.2 states that it is primarily the slope in the LE between the jump-off year of the forecast and the year 2030/2050 that is under-predicted, not so much the level. Following this line of thought, Ascher's theory of assumption drag applies to improvements in the LE, rather than LE levels. The consequence may very well be that in future population forecasts, the downward revisions in Figs. 9.3 and 9.4 will come to a halt and that more or less stable patterns will emerge. This is more likely for 2030 than for 2050. After all, the closer we get to a certain target year, the easier it becomes to predict the LE for that year. Obviously, there is one additional important assumption underlying these speculations, namely that the long-term trend in LE expectancy is definitely upward, and that any periods of stagnation are only temporary.

\subsubsection{Anchoring}

The anchoring effect is one of the most solid tested phenomena in the world of experimental psychology. Tversky and Kahneman (1974; see also Kahneman 2011) discovered a cognitive bias, which takes place when we consider a particular value of an unknown quantity before estimating such quantity. The value we have considered or that has been shown to us before, strongly determines the estimate we are going to make, which will always be relatively close to that previous value, which is called the anchor. Once the anchor has been established, we evaluate whether it is high or low and then we adjust our estimate to that amount. This mental process finishes early, because we are not sure of the real amount. Therefore, our estimation is not usually far from the anchor. Thus, the idea of an adjust-and-anchor heuristic as a strategy for estimating uncertain quantities is as follows. Start from an anchoring number, assess whether it is too high or too low, and gradually adjust your estimate by mentally "moving" from the anchor. The adjustment typically ends 
prematurely, because people stop when they are no longer certain that they should move farther.

We can use the theory of anchoring to explain the patterns that we see in Figs. 9.1, 9.2, 9.3 and 9.4. To fix ideas, consider a forecast made every 3 years; let us say in 2012, 2015, and 2018. A forecaster confronted with the task of extrapolating LE between 2012 and 2030 uses recently observed values as an anchor. In spite of the fact that historical values have increased more or less linearly at a certain pace, a simple straight-line extrapolation with the same slope would move the prediction for 2030 too far away from the anchor value, and the forecaster decides to extrapolate with smaller annual improvements than historically. This may be a straight line, or, a decelerating (concave) curve. The next forecast round starts from the LE observed for 2015, and moves the complete extrapolated line or curve upwards. This is in essence the process described by the model in Sect. 9.2.2. Because the extrapolations do not increase fast enough, the new prediction for 2030 is higher than the old one for the same year. The whole procedure is repeated for 2018, and the result is an even higher LE-prediction for 2030. Figure 9.6 illustrates this process for the case of the United Kingdom.

Figure 5: Successive projections of period life expectancy at birth, males: UK, 1966-2030

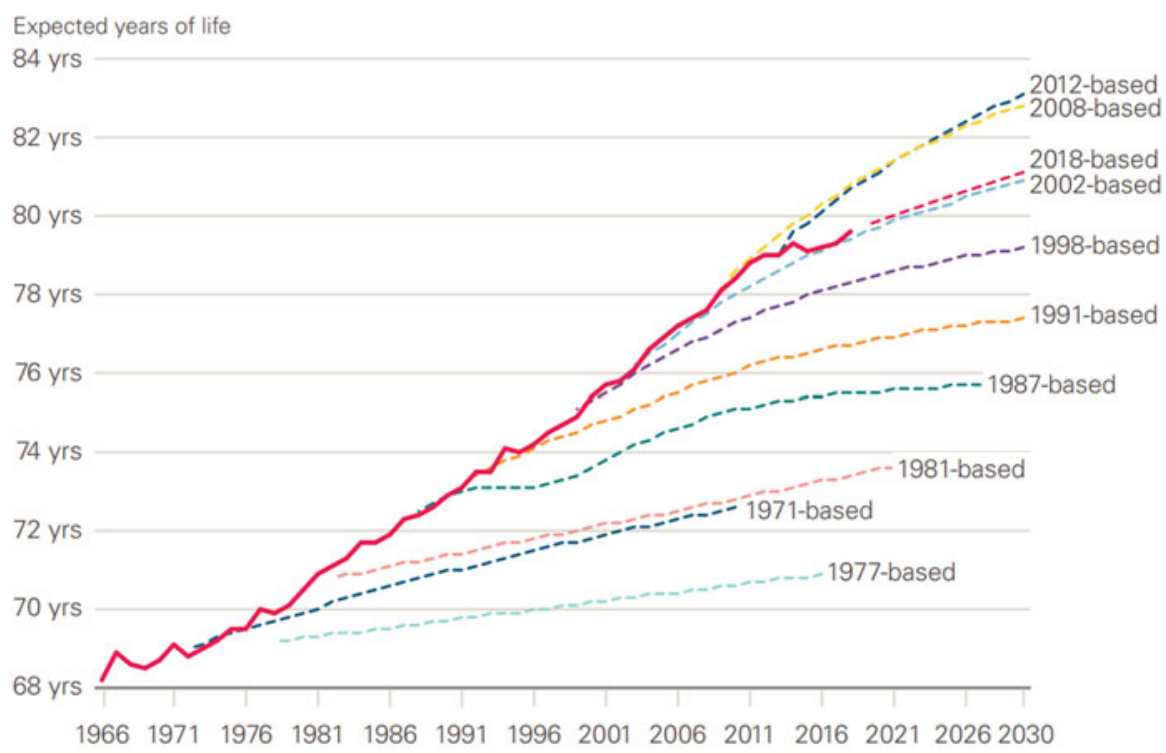

Source: ONS National Population Projections Accuracy Report underlying data, UK, 1966 to 2030; expectation of life, principal projection, United Kingdom, 2012-based, 2014-based and 2018-based.

Fig. 9.6 Actual and projected period expectation of life at birth (EOLB), males, United Kingdom, 1966 to 2030 , selected projections. 
Between 1985 and 2012, the Office for National Statistics (ONS) did not extrapolate the LE according to a straight line, but used a concave curve. As argued in Sect. 9.2, not only extrapolations based on proportionate changes in age-specific mortality, but also those based on the Lee-Carter model will result in LE-improvements that diminish over time. In Sect. 9.2.2, we demonstrated that even with straight-line extrapolations, we would observe systematic upward revisions of predicted LEs for a certain target year if the slope of the extrapolation were less steep than that of actual values. This was the case for ONS-forecasts between 1971 and 1981 in Fig. 9.6.

The discussion so far attempts to explain the patterns in Figs. 9.1 and 9.2, where LE-predictions are systematically revised upwards. However, we can also use the theory of anchoring behaviour to explain downward revisions as in Figs. 9.3 and 9.4. When actual LE stagnates, the anchoring effect becomes stronger, and the extrapolations in the previous round of forecasts are considered too steep. As a result, the revised extrapolation curve is flatter than the original one, leading to a revised 2030-prediction that is close to the value in the previous round. This may explain the patterns we see for Danish men and women after 2011 in Figs. 9.1 and 9.2, and for Austrian men and women for forecasts with jump-off years between 2009 and 2015. Very strong anchoring may even lead to a downward revision; cf. the cases of Sweden and the UK in particular.

Kahneman (2011) notes that there are situations in which anchoring appears reasonable. People who are asked difficult questions clutch at straws, and the anchor is a plausible straw. To predict long-term trends in mortality is clearly difficult. Therefore, it is reasonable to use actual mortality trends as anchors. Yet one may wonder if forecasters, once being aware of the anchoring effect when formulating forecast assumptions, will learn from the errors they made in the past?

\subsection{Conclusions}

Life expectancy predictions for a certain target year (for instance, 2030, or 2050) computed by statistical agencies in some countries during the past decade have been revised upwards frequently. We noticed this in official LE-predictions for Denmark, Japan, and Norway. However, for a number of other countries (viz. Austria, the Netherlands, Sweden, the United Kingdom), such upward revisions are no longer visible. The LE-adjustments for 2030 and 2050 appear to be very small - they are even negative in the most recent forecasts for these countries. This means that in the current forecast, the forecaster is less optimistic about the LE in the target year than she was in the previous forecast. One possible explanation is that actual LE did not improve much, perhaps even stagnated, during the period between two forecasts. The patterns described here, illustrated by Figs. 9.1, 9.2, 9.3 and 9.4, are compatible with a situation in which the real (but unknown) LE until 2030 or 2050 improves faster than the predicted LE. We referred to two psychological factors that can be used to explain these patterns. The first one is an assumption drag, a term 
first coined by Ascher in 1978 in connection with fertility forecasts in developed countries in the 1960s, which tended to be far too high. The assumption drag involves a psychological mechanism according to which forecasters rely heavily on recently observed data, whereas they give less weight to long-term trends. The second psychological mechanism that one may use to explain upward and downward revisions of the LE in a series of population forecasts is an anchoring effect, discovered by Tversky and Kahneman. When a forecaster has to predict an unknown and uncertain quantity, he will start from a known value (the anchor), and predict a value that is close to that value.

The process with upward or downward revisions of predicted LE for a certain year in the future resembles the behaviour of a hunter, who aims at a moving target. Sometimes the target moves up (upward revision of the LE), sometimes down (downward revision). However, a simple model based on linear extrapolations of the LE suggests that upward revisions result simply from the fact that extrapolated LE does not improve as fast as actual LE. Downward revisions may be the result of a temporary stagnation of LE-improvement.

Acknowledgements We acknowledge gratefully the help of Alexander Hanika (Statistics Austria) and Annika Klintefelt (Statistics Denmark) in collecting data on historical forecasts for the two countries.

\section{Appendix: Data Sources}

Frank Hansen, M., Stephensen, P. (2013). Danmarks Fremtidige Befolkning: Befolkningsfremskrivning 2013.

Alexander Hanika (2019) Personal communication.

National Institute of Population and Social Security Research - IPSS (2012). http://www.ipss.go.jp/syoushika/tohkei/newest04/h4_2.html. Accessed: October 2018.

IPSS (2007). http://www.ipss.go.jp/syoushika/tohkei/suikei07/houkoku/katei/ 11-5.xls. Accessed: October 2018.

IPSS. http://www.ipss.go.jp/syoushika/tohkei/Mokuji/1_Japan/J_Detail_14.asp? fname $=1 \_$katei $/ 1-2 . h$ tm\&title $1=\% 82 \mathrm{P} \% 81 \mathrm{D} \% 89 \% \mathrm{BC} \% 92 \% \mathrm{E} 8 \% 921 \% 95 \% 5 \mathrm{C} \&$ title2=\%95\%5C\%82P\%81\%7C\%82Q\%81D\%89\%BC\%92\%E8\%82\%B3\%82 \%EA\%82\%BD $\% 95 \% \mathrm{BD} \% 8 \mathrm{~B} \% \mathrm{CF} \% 8 \mathrm{E} \% \mathrm{~F} 5 \% 96 \% \mathrm{BD} \% 81 \mathrm{i} \% 8 \mathrm{Fo} \% 90 \% \mathrm{~B} 6 \% 8 \mathrm{E}$ $\% 9 \mathrm{E} \% 82 \% \mathrm{CC} \% 95 \% \mathrm{BD} \% 8 \mathrm{~B} \% \mathrm{CF} \% 97 \% 5 \mathrm{D} \% 96 \% \mathrm{BD} \% 81 \mathrm{j} \% 82 \% \mathrm{CC} \% 90 \% 84$ $\% 88 \%$ DA. Accessed: October 2018.

IPSS. http://www.ipss.go.jp/ppzenkoku/e/zenkoku_e2017/g_images_e/pp29gt 0402e.files/sheet001.htm. Accessed: October 2018.

Office for National Statistics - ONS (2001). https://webarchive.nationalarchives. gov.uk/20160106011038/; http://www.ons.gov.uk/ons/rel/npp/national-populationprojections-historic-series/2000-based-projections/index.html. Accessed: October 2018. 
ONS (2003). https://webarchive.nationalarchives.gov.uk/20160106011038/; http://www.ons.gov.uk/ons/rel/npp/national-population-projections-historic-series/ 2002-based-projections/index.html. Accessed: October 2018.

ONS (2005). https://webarchive.nationalarchives.gov.uk/20160106011038/; http://www.ons.gov.uk/ons/rel/npp/national-population-projections-historic-series/ 2004-based-projections/index.html. Accessed: October 2018.

ONS (2007). https://webarchive.nationalarchives.gov.uk/20160105223341/; http://www.ons.gov.uk/ons/rel/npp/national-population-projections/2006-basedprojections/index.html. Accessed: October 2018.

ONS (2009). https://webarchive.nationalarchives.gov.uk/20160105223341/; http://www.ons.gov.uk/ons/rel/npp/national-population-projections/2008-basedprojections/index.html. Accessed: October 2018.

ONS (2011). https://webarchive.nationalarchives.gov.uk/20160105223341/; http://www.ons.gov.uk/ons/rel/npp/national-population-projections/2010-basedprojections/index.html. Accessed: October 2018.

ONS (2013). https://webarchive.nationalarchives.gov.uk/20160105223341/; http://www.ons.gov.uk/ons/rel/npp/national-population-projections/2012-basedprojections/index.html. Accessed: October 2018.

ONS (2015). https://webarchive.nationalarchives.gov.uk/20160105223341/; http://www.ons.gov.uk/ons/rel/npp/national-population-projections/2014-basedprojections/index.html. Accessed: October 2018.

ONS (2017). National Population Projections: 2016-based statistical bulletin. https://www.ons.gov.uk/peoplepopulationandcommunity/populationandmigration/ populationprojections/bulletins/nationalpopulationprojections/2016basedstatistical bulletin. Accessed: October 2018.

ONS (2018). https://www.ons.gov.uk/peoplepopulationandcommunity/births deathsandmarriages/lifeexpectancies/datasets/nationallifetablesunitedkingdom referencetables. Accessed: October 2018.

Kaneko, R., Ishikawa, A., Ishii, F., Sasai, T., Iwasawa, M., Mita, F. and Moriizumi, R. (2006). Population projections for Japan: 2006-2055 outline of results, methods, and assumptions.

Statistics Denmark (2019). Population Projections for Denmark. https://www. dst.dk/en/Statistik/emner/befolkning-og-valg/befolkning-og-befolkningsfrems krivning/befolkningsfremskrivning. Accessed: January 2019.

Statistics Denmark. https://www.dst.dk/da/Statistik/Publikationer/StE/statistiskeefterretninger-emner?psi=486. Accessed: October 2018.

Statistics Netherlands (2019). https://opendata.cbs.nl/\#/CBS/nl/navigatieScherm/ zoeken?searchKeywords $=* \&$ page $=1 \&$ year $\% 5 \mathrm{~B} \% 5 \mathrm{D}=$ Prognose. Accessed: June 2019.

Statistics Sweden (2002). https://www.scb.se/statistik/BE/BE0401/2003M00/ BE18SM0201.pdf. Accessed: October 2018.

Statistics Sweden (2003). http://www.scb.se/statistik/BE/BE0401/2003I50/ BE51ST0304.pdf. Accessed: October 2018.

Statistics Sweden (2004). http://www.scb.se/statistik/BE/BE0401/2003M00/ BE0401_2004A01_SM_BE18SM0401.pdf. Accessed: October 2018. 
Statistics Sweden (2005). https://www.scb.se/statistik/BE/BE0401/2005A01/ BE0401_2005A01_SM_BE18SM050 1.pdf. Accessed: October 2018.

Statistics Sweden (2006). http://www.scb.se/statistik/_publikationer/BE0401_ 2006I50_BR_BE51ST0602.pdf. Accessed: October 2018.

Statistics Sweden (2018). Sveriges framtida befolkning 2018-2070. https://www. scb.se/hitta-statistik/statistik-efter-amne/befolkning/befolkningsframskrivningar/ befolkningsframskrivningar/pong/publikationer/sveriges-framtida-befolkning20182070/. Accessed: October 2018.

Statistics Sweden (2007). http://www.statistikdatabasen.scb.se/goto/en/ssd/ PrognosLivslangd04. Accessed: October 2018.

Statistics Sweden (2008). http://www.statistikdatabasen.scb.se/goto/en/ssd/ BefPrognosLivslangd. Accessed: October 2018.

Statistics Sweden (2009). http://www.statistikdatabasen.scb.se/goto/en/ssd/ BefPrognosLivslang09. Accessed: October 2018.

Statistics Sweden (2010). http://www.statistikdatabasen.scb.se/goto/en/ssd/ BefProgLivslangd2010. Accessed: October 2018.

Statistics Sweden (2011). http://www.statistikdatabasen.scb.se/goto/en/ssd/ BefProgLivslangd2011. Accessed: October 2018.

Statistics Sweden (2012). http://www.statistikdatabasen.scb.se/goto/en/ssd/ BefProgLivslangd2012. Accessed: October 2018.

Statistics Sweden (2013). http://www.statistikdatabasen.scb.se/goto/en/ssd/ BefProgLivslangd2013. Accessed: October 2018.

Statistics Sweden (2014). http://www.statistikdatabasen.scb.se/goto/en/ssd/ BefProgLivslangd2014. Accessed: October 2018.

Statistics Sweden (2015). http://www.statistikdatabasen.scb.se/goto/en/ssd/ BefProgLivslangd2015. Accessed: October 2018.

Statistics Sweden (2016). http://www.statistikdatabasen.scb.se/goto/en/ssd/ BefProgLivslangd2016. Accessed: October 2018.

Statistics Sweden (2017). http://www.statistikdatabasen.scb.se/goto/en/ssd/ BefProgLivslangd2017. Accessed: October 2018.

\section{References}

Ascher, W. (1978). Forecasting: An appraisal for policy makers and planners. Baltimore: Johns Hopkins University Press.

Bengtsson, T., \& Keilman, N. (Eds.). (2019). Old and new perspectives on mortality forecasting. Cham: Springer.

Booth, H., \& Tickle, L. (2008). Mortality modelling and forecasting: A review of methods. Annals of Actuarial Science, 3(1 \& 2), 3-43.

Kahneman, D. (2011). Thinking, fast and slow. London: Penguin Books.

Keilman, N. (2018). Increasing (but Insufficient?) Optimism about future life expectancy. NIUSSP 15 October 2018.

Keilman, N., Cruijsen, H., \& Alho, J. (2008). Changing views of future demographic trends. In J. Alho, S. Hougaard Jensen, \& J. Lassila (Eds.), Uncertain demographics and fiscal sustainability (pp. 11-33). Cambridge: Cambridge University Press. 
Keyfitz, N., \& Caswell, H. (2005). Applied mathematical demography (3rd ed.). New York: Springer.

Lee, R. (1980). Aiming at a moving target: Period fertility and changing reproductive goals. Population Studies, 34(2), 205-226.

Lee, R. D., \& Carter, L. R. (1992). Modeling and forecasting US mortality. Journal of the American Statistical Association, 87(419), 659-671.

Oeppen, J., \& Vaupel, J. (2001). Broken limits to life expectancy. Science, 296(5570), 1029-1031.

Pison, G. (2018). 1968-2018: Four demographic surprises in France over the last 50 years. Population \& Societies, 553, 1-6.

Stoeldraijer, L., Van Duin, C., \& Huisman, C. (2017). Bevolkingsprognose 2017-2060: 18,4 miljoen inwoners in 2060 (Population forecast 2017-2060: 18.4 million inhabitants in 2060). Statistische Trends, December 2017.

Stoeldraijer, L., Van Duin, C., Van Wissen, L., \& Janssen, F. (2018). Comparing strategies for matching mortality forecasts to the most recently observed data: Exploring the trade-off between accuracy and robustness. Genus, 74(16), 1-20.

Tversky, A., \& Kahneman, D. (1974). Judgment under uncertainty: Heuristics and biases. Science, 185(4147), 1124-1131.

Open Access This chapter is licensed under the terms of the Creative Commons Attribution 4.0 International License (http://creativecommons.org/licenses/by/4.0/), which permits use, sharing, adaptation, distribution and reproduction in any medium or format, as long as you give appropriate credit to the original author(s) and the source, provide a link to the Creative Commons license and indicate if changes were made.

The images or other third party material in this chapter are included in the chapter's Creative Commons license, unless indicated otherwise in a credit line to the material. If material is not included in the chapter's Creative Commons license and your intended use is not permitted by statutory regulation or exceeds the permitted use, you will need to obtain permission directly from the copyright holder.

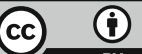

